\title{
A potential limit on competition
}

\section{Christian Cordes}

Published online: 1 July 2008

(C) The Author(s) 2008

\begin{abstract}
The paper analyzes the ambiguous interplay of some human cognitive dispositions and competitive forces: (a) people have a want for a certain amount of novelty-potentially induced by competition-driven innovation-but emotionally resist an excessive degree of novel mental experiences; and (b) competition-driven change introduces challenges to agents that may result in fluid life states when skills and cognitive resources enable an individual to meet these challenges or in strained life states if this is not the case. As a result, some affective constraints to economic development and potential implications for economic theory development and policy making are identified.
\end{abstract}

Keywords Competition $\cdot$ Well-being $\cdot$ Novelty $\cdot$ Policy making

JEL classification $\quad \mathrm{D} 01 \cdot \mathrm{I} 31 \cdot \mathrm{O} 33 \cdot \mathrm{D} 60 \cdot \mathrm{B} 52$

\section{Introduction}

This paper shows that there are potential limits to economic dynamics that are to be found within human beings and that have not been, hitherto, the subject matter of economic theory. The proposed approach adds some cognitive and affective aspects to a behavioral model of economic agents.

Affective primordial components of the human brain, evolved during human phylogeny, provide the grounding for the capacities of humans' more recently evolved cognitive apparatus (Panksepp 2003a). Consequently, there are strong linkages between

C. Cordes (凶)

Max Planck Institute of Economics Evolutionary Economics Group,

Kahlaische Str. 10, 07745 Jena, Germany

e-mail: cordes@econ.mpg.de 
consciousness and affect (see, example, Kaufman 1999). These affective dispositions contribute to an explanation of biases in humans' attention in receiving information, choosing stored information for further cognitive processing, decision making, and the determinants of subjective well-being.

The paper's approach is based on the continuity hypothesis (Witt 2003b, 15f, 2004). This hypothesis represents a way of showing how Darwinian theory is relevant for economics: the human species is a result of natural (Darwinian) evolution; natural evolution has shaped the ground and still defines the constraints for human-made, or cultural, evolution. The historical process of economic evolution can be conceived as emerging from, and being embedded in, the constraints shaped by evolution in nature. Darwinian theory explains the origins of economic evolution in human phylogeny and fosters the understanding of the lasting influence of innate elements, dispositions, and programs on behavior, which result from the forces of natural selection and which impose limitations on cultural evolution.

Competition is a determinant of economic change and variance of human behavior. It is regarded as a progressive element in the dynamics of capitalism causing the ceaseless economic movement and transformation across time and space (see Metcalfe 2001). Innovation is the driving force behind much of competition and, conversely, competition drives innovation. Economic evolution proceeds through the generation of variety in competition (Nelson 1990). By referring to insights from cognitive neuroscience, physiology, and psychology, it will be shown how human agents affectively evaluate novelty and perceived challenges that emerge in a dynamic competitive environment. As a result, some affective constraints upon economic development are identified. Moreover, it will be expounded how these findings relate to theory development in economics, especially in the realms of welfare and normative economics.

The paper proceeds as follows: Section 2 shows how humans affectively evaluate different amounts of novel mental experiences. Section 3 examines the connections between an agent's skills and cognitive resources on the one hand, and challenges posed by the environment on the other. Again, the resulting affectively evaluated life states are taken into account. Section 4 presents some implications of the insights gained for economic theory and policy making. It is shown that limits to economic dynamics exist within human beings. Finally, Section 5 offers some conclusions.

\section{The first ambiguity: the human want for novelty}

Humans enjoy a certain amount of novel mental experiences. Excitement through novelty is an important form of human satisfaction (Piaget 1952; Scitovsky 1981; Loewenstein 1994; Zuckerman 1994; Bardo et al. 1996; Bianchi 2002). However, as will be shown below, the desire for experiencing a certain amount of novelty is subject to deprivation and satiation.

Established findings from psychology show that young infants prefer novel stimuli (see, example, McCall et al. 1977; Ranganath and Rainer 2003). However, the want for novelty is a behavioral tendency manifested not only by human infants, but also by human adults and animals (see, example, Najm-Briscoe et al. 2000). An agent's capability to distinguish between what is novel and what has already been experienced, or 
between degrees of novelty, and to (affectively) evaluate those events for subsequent behavioral action encompasses fundamental cognitive processes, enabling humans to appropriately react to stimuli in their environment.

Findings from cognitive neuroscience have demonstrated the existence of specialized neural mechanisms for detecting, attending to, and remembering of novel events. The underlying physiology and neuroanatomical substrates of the brain's response to novel events have been the subject matter of many inquiries (for a review of this literature see Friedman et al. 2001; Ranganath and Rainer 2003). Prefrontal, cortical, and parietal neurons, for example, respond more strongly to novel than to familiar stimuli, i.e., they exhibit a preference for novelty. A complex network of brain regions and processes responds to stimuli that are novel.

Another powerful behavioral tendency is an organism's inclination to prefer pleasant over aversive stimuli. The human brain is capable of elaborating an affective form of consciousness that belongs to its motivational systems and is built upon neural systems that monitor bodily states (Buck 1985; Panksepp 2003a). In this way, positive affective experiences enable humans to engage aspects of the world in ways that are valuable in sustaining life and well-being, while negative affective experiences inform humans of aspects that should be avoided because they compromise life and well-being (see also Kahneman et al. 1997). Alongside the perception of the state of the body, there is the perception of thoughts and certain modes of thinking in higher brain regions with contents consonant with the emotion, i.e., the affective evaluation of these states (Damasio 2003, p. 85). The combination of these perceptions constitutes a feeling state.

Different degrees of novelty have different behavioral effects and are evaluated affectively in different ways (Maddi 1961b; Scitovsky 1981; Wasserman et al. 2004). ${ }^{1}$ Moderately novel situations or episodes characterized by a moderate proportion of elements that differ from those of preceding situations or episodes, do produce pleasant stimuli and approach behavior. ${ }^{2}$ Some variation in stimulation is sought out by the organism and is required for normal development and functioning (Fiske and Maddi 1961; Zuckerman 1994; Bardo et al. 1996). On the other hand, extremely novel situations or episodes characterized by a large proportion of elements that differ from the ones of preceding situations or episodes or that include elements which are unique in the life history of an organism are experienced as unpleasant and trigger avoidance behavior (Maddi 1961a; Wasserman et al. 2004).

In this context, the degree or amount of novelty that an agent encounters is a compound variable consisting of the novelty's content and the frequency of novel stimulation, which both determine stimulus intensity. A rare single event in an organism's environment may have a high novelty content that triggers intensive affective reaction. On the other hand, there may be frequent stimuli carrying a moderate novelty content

\footnotetext{
1 According to norm theory (Kahneman and Miller 1986), novel events elicit especially strong Good/Bad values by emotional amplification.

2 Novel stimuli comprise either stimuli that are different from recently experienced stimuli, or stimuli which are to some extent unprecedented in the organism's history (see Maddi 1961a). The first type of novelty is relative, while the second is more absolute. In the context of this paper, novelty is most adequately defined with regard to the subjective representation of past experience.
} 
that amount to a similar affective evaluation. The overall affective evaluation of an episode is determined by the relative frequencies, duration, and intensity of affective experiences (see Kahneman 1999). Hence, within the scope of the approaches drawn upon in this paper, the multidimensional variable 'novelty' is collapsed into a unidimensional quantity.

An inverted U-shaped relation between the degree of novelty (as the independent variable) and some measure of an agent's well-being (as the dependent variable) can be assumed. There are-in a psycho-physiological context-areas of excitation and positive excitability and inhibition and negative excitability by novel stimuli (see McCall et al. 1977; Anderson 1990). ${ }^{3}$ Moreover, novelty contributes in determining an organism's level of neurophysiological activation or arousal (Steriade 1996) and thus influences the affective evaluation of situations. ${ }^{4}$ Fiske and Maddi (1961) have argued that, to a considerable extent, affect is a function of the discrepancy between actual and characteristic levels of activation or arousal, i.e., large discrepancies are ordinarily associated with negative affect (unpleasant), while positive affect (pleasant) is experienced when such discrepancies are reduced (see also Ursin and Eriksen 2004). ${ }^{5}$

In a similar manner, Berlyne (1960, p. 194, 1971) argued, in his path-breaking research on curiosity, that there is an optimal influx of arousal potential for an individual organism. He claimed that the human desire for novelty serves as a regulating mechanism of states of arousal or activation and, closely connected to this, the capacity to sustain attention to the external world. Arousal potential that deviates in either an upward or a downward direction will be aversive.

According to neuropsychological findings, organisms are motivated to alter environmental inputs, i.e., to reduce stimulus variability when too much is present and to increase variability when stimulation falls below some optimal level (see, example, Berlyne 1960, Ch. 8; Zuckerman 1994). Further, the rate of arousal potential that is optimal varies - within certain boundaries - from individual to individual, partly due to their respective socialization history or cultural peculiarities (Revelle and Loftus 1990). Hence, individuals show differences in the intensity and quality of their variation-seeking. Some agents are relatively more interested in, and disposed toward, the occurrence of change, novelty, and the unexpected (Maddi 1961a). Furthermore, within certain boundaries, continuous exposure to a complex environment shifts the arousal function toward a need for greater complexity (Mayes 1991).

Overall, an organism's activation level is determined by stimulation-including novelty-stemming from exteroceptive, interoceptive, and cerebral sources

\footnotetext{
3 This is similar to arguments derived from Wundt's Law (Wundt 1894), which states that the perceived magnitude and quality of a stimulus is judged relative to the prevailing adaptation level of an agent.

4 Within boundaries, novelty responses habituate across successive presentations of novel items (Ranganath and Rainer 2003). As stimuli become more predictable, the magnitude of novelty response wanes. However, high arousal triggered by stimuli associated with unpleasant experiences are highly resistant to habituation.

5 There are also other determinants of affective states. Some levels of activation well above normal can be accompanied by positive affect, as in the case of sexual activity (see, example, Fiske and Maddi 1961). Moreover, slight and transitory jumps in arousal are often pleasurable as a consequence of the drop in arousal that quickly terminates them (Berlyne 1960, p. 199). In contrast, a sustained increase in arousal is experienced as unpleasant.
} 
(see Fiske and Maddi 1961). At the same time, agents are disposed to maintain their normal level of activation (or arousal potential). ${ }^{6}$ Hence, on the one hand, organisms seek to experience variation in order to sustain a normal level of activation. This endeavor provides the motivational underpinnings of explorative behavior: in case of a lack of novelty, the activation level is exceptionally low and the agent is motivated to alleviate this situation (see Berlyne 1960, 163ff; Maddi 1961a; Revelle and Loftus 1990). ${ }^{7}$ The extent of deviation of a stimulus from previously experienced stimuli can be considered the novelty of a stimulus that determines its arousal potential and thus its suitability to meet an agent's want to experience variation.

On the other hand, when stimuli are very intense and activation is consequently high, exceeding the preferred level, discomfort, distress, or pain is experienced. A too high level of activation is unpleasant and associated with such affective states as inability to concentrate, anxiety, or rapid heart beat (Fiske and Maddi 1961; Kaufman 1999). The agent is motivated to avoid such a situation.

When agents are confronted with a high amount of novel stimuli, there are certain kinds of novelty, such as innovations in consumption goods, that can be avoided by ignoring them-although it may not be easy to so, for example, ignore a fashion in one's peer group. However, many novelty-driven dynamics eventually generated by competition cannot be avoided: new technologies at the workplace, change of the place of residence due to restructuring firms, new modes of employment, changing social institutions and welfare systems, a faster pace of introduction of new products and processes in a globalized economy, etc.

This section's thoughts lead to the following hypothesis:

Hypothesis 1 Human agents react positively toward a certain amount of novel mental experience. On the other hand, when novel stimuli exceed this amount, these are associated with negative affect, avoidance behavior is triggered, and well-being is impaired. Therefore, the human want for novelty has limits imposed on it by psychophysiological factors.

\section{The second ambiguity: fluid versus strained life states}

The human brain is prepared by natural evolution to respond to certain emotionally competent stimuli and learns many more of such stimuli during its lifetime. It is the ultimate goal of these responses to place the organism in circumstances conducive to survival and well-being (Damasio 2003, p. 53). Moreover, organisms strive to achieve a better than neutral life state, i.e., they try to enhance their well-being. This is the aim of the ensemble of the body's homeostatic regulations and the body-sensing brain regions, i.e., neural patterns that portray responses to emotionally relevant events, that continuously map an organism's body state (Damasio 1996, 2003, pp. 35, 65). Human agents are motivated to create the most beneficial situation for their own selfpreservation and efficient functioning of their body. Joyous states of the body indicate

\footnotetext{
6 Activities or responses that change the level of stimulation toward normal stimulation exhibit reinforcing value (see Leuba 1955).

7 Humans' need for a certain amount of novelty manifests, for example, in innovations on the demand side.
} 
optimal psycho-physiological coordination and smooth running of the operations of life (Damasio 2003, p. 137; Panksepp 2003a).

A crucial determinant of the quality of an emotional state is whether the life governance processes are either strained or fluid (Damasio 2003, 131f). Fluid life states are naturally preferred; strained life states are naturally avoided. Bechara et al. (2000) have found structures in ventromedial prefrontal cortex that provide the substrate for learning an association between classes of complex situation and the type of bioregulatory state including emotional state that is usually associated with that class of situation in past individual experience. The somatic state indicates the goodness or badness of a certain situation. Memory of the felt situation promotes the avoidance of situations associated with negative feelings and the seeking of situations that may cause positive feelings (Damasio 2003, p. 178; Panksepp 2003b). Emotions and feelings guide a deliberate endeavor of self-preservation.

Moreover, while experiencing an emotional event, the orbitofrontal cortex of the brain, which monitors and controls emotional responses, informs the organism of the consequences (pleasant/unpleasant) of an agent's actions (see, example, Rule et al. 2002). This region is also important for remembering the affective quality of prior emotional experiences. Living organisms are designed with an ability to react emotionally to different objects, states, and events followed by a variation of pleasure or pain and a pattern of feeling in higher brain regions (Damasio 2003, p. 11). Every content of conscious states needs to be grounded on the regulatory and emotional states of the whole organism (see Thompson and Varela 2001).

The importance of affect for human behavior becomes obvious in the case of people who suffered from a damage to regions of the frontal lobe that normally engage emotions in relation to complex situations and events. They become unable to, for example, observe social conventions and unable to decide advantageously on matters pertaining to their own lives (see Bechara et al. 2000). Emotions and feelings play an important role in impaired decision making. What is more, the capacity to experience affect informs humans about what is good, bad, and neutral in their environments.

A particular type of an agent's affective experience that can happen in many different kinds of activity and that is characterized by feelings of fusion with an ongoing activity, effortlessness, focused concentration, order, and fluidity has been termed 'flow experience' in psychology. 'Flow', as an observable regularity in human behavior, has become a technical term in the field of intrinsic motivation. It is one means that helps organisms to identify situations that increase subjective well-being. Moreover, it is a well-established physiological fact that there are organism states in which the regulation of life processes becomes efficient, optimal, free-flowing, and easy (Damasio 2003, p. 131).

The underlying 'flow concept' has been articulated by Csikszentmihalyi (1990, 1993). Flow is obtained when the contents of consciousness are in harmony with each other and with the goals that define an agent's self. Activities connected to this kind of experience are motivated foremost by sheer enjoyment of the activity itself rather than its results or external rewards. The term 'flow' denotes a process in which an agent feels in control of his actions, in which action follows upon action according to an internal logic with nearly no conscious intervention, and in which there is little distinction between stimulus and response. The tasks undertaken have clear goals and 
provide immediate feedback. Flow experiences produce intense feelings of enjoyment and creativity. ${ }^{8}$ Moreover, flow experiences manifest in subjective conditions humans call pleasure, happiness, satisfaction, or enjoyment (Csikszentmihalyi 1992, p. 24). Hence, one goal of the self is to keep on experiencing flow. In addition, as a central aspect of flow, personal skills and cognitive resources are experienced as according well with the given challenges.

There are two conditions beyond flow, both representing a state of imbalance between challenge and skill-boredom and anxiety. First, in the case of boredom, people have to increase the complexity of the activity by developing new capabilities and taking on new challenges. There is then a positive attraction of problem solving and mild frustration (Berlyne 1960, p. 214; Munsinger and Kessen 1966). Second, when the environment typically presents challenges significantly greater than an agent's skills and cognitive resources as well as his capability to adapt these, then life takes on a predominantly strained quality and capacities are overstressed.

Moreover, due to an overly challenging environment, experienced uncertainty spreads beyond a limited stimulus field and triggers negative affect (see Mitchell 1992). ${ }^{9}$ In this context, uncertainty is experienced when challenges such as new social encounters or problem presentations are largely unrelated to previous social interaction or problems, unpredictable by known rules, or unstructured and foreign. Consequently, the effects of an agent's acts—representing his skills—upon others or those problems remain uncertain. People then tend to strive for stability, predictability, security, and certainty, i.e., they try to rematch skills and challenges. ${ }^{10}$ Continued uncertainty leads to chronic excitement or tension that is almost always affectively evaluated in a negative way. The dislike of excessive uncertainty seems to be a universal human trait (Scitovsky 1981; see also Commons 1921).

Modern societies are characterized by challenges resulting from human interventions in the conditions of socio-economic life and nature. Giddens (1994, Ch. 6) terms these challenges 'manufactured risks'. Furthermore, he says that the quality of life essentially consists of an agent's capacity to respond to the challenge of manufactured risk. Therefore, as Csikszentmihalyi (1990, 208ff) argues, happiness is not the product of passive enjoyment but of the capacity to transform challenges into an orderly sequence of actions, in which the challenges encountered accord with the ability to respond to them (see also Peterson 1999).

As has been shown, the universal precondition for flow is a balance between the challenges perceived in a given situation and the skills and cognitive resources an agent brings to it (Csikszentmihalyi 1990, p. 30). Various possibilities for action that fulfill this correspondence can produce a flow experience. Moreover, actors can be thought of as seeking to bring into balance their perceived skills and cognitive resources on the one hand, and the responsibilities and challenges confronting them on the other. Therefore, affective well-being is indirectly influenced by the amount of (cognitive) resources and skills that people have at their disposal to achieve their goals and meet

\footnotetext{
8 Many new ideas, artifacts, or technologies have been discovered in activities that had no practical goal but were intrinsically motivated by flow experiences.

9 In addition, uncertainty is increasing as an inevitable concomitant of novelty.

10 Kagan (1972) has maintained that there is a basic human motive to resolve uncertainty.
} 
their challenges. This amount potentially increases the probability of flow experiences that are associated with positive affect (see, example, Emmons 1986). Environments in which this is beyond an agent's capabilities will be affectively evaluated in a negative way (see also Morris 1999).

White (1959) argued that an individual's set of skills (or, in his terms, competences) represents an independent motivational system. According to his conceptualization, competence is motivated by 'effectance', i.e., the feeling of pleasure and satisfaction experienced when an agent understands a phenomenon or achieves a result (see also Kaufman 1998). Aspects of a task encountered influence feelings of effectance and affective evaluation inasmuch as the stimulus needs to be challenging but not excessively so that it cannot be mastered (see also Ursin and Eriksen 2004). Several inquiries have shown that there is a close interrelationship between positive affect and problem solving (see, example, Cicchetti and Pogge-Hesse 1981). In their neuropsychological account, Ashby et al. (1999), for example, assume that creative problem solving and coping skills are improved by and can trigger an increase in dopamine release in the anterior cingulate that is associated with positive affect and that positively influences cognitive flexibility, working memory, and facilitates executive attention.

The argument leads to the following hypothesis:

Hypothesis 2 If an agent's skills and cognitive resources are experienced as according well with the challenges posed by an environment, his life state may be fluid. However, situations in which skills and cognitive resources are insufficient to cope with challenges are affectively evaluated in a negative way and result in strained life states. In that case, human well-being is impaired.

\section{Some implications for economic theory and policy making}

Given that Hypotheses 1 and 2 hold, this section offers some thoughts in regard to the potential implications of the human psycho-physiological dispositions mentioned above for development of economic theory and policy making related to competitive environments.

Economic research focuses almost exclusively on the questions of how to promote competition and elicit innovations. Societal progress emanating from innovative activities gave rise to the hypothesis that the greater the pace of innovativeness in an economic system, the more per capita real income and overall well-being is generated in the long run (see Witt 1996). However, the potential limits of competition, for example, when taking into account human well-being, have not been the subject matter of economics. ${ }^{11}$ A frequent implicit assumption in the policy making debate is that innovativeness-i.e., the introduction of novelty to the economic system-is by and large beneficial and should therefore be fostered politically (Witt 2003a). But, as shown in this paper, a faster pace of innovation is not sufficient to guarantee increasing well-being. A high competition-driven pace of innovative economic activities may imply welfare losses for many members of society.

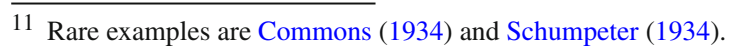


$\mathrm{Ng}$ (2003) claimed that welfare economics is incomplete in its depth of analysis as it stops at the level of preference and does not include an analysis of well-being, which is, in his words, the ultimate level. Striving for well-being or happiness, Ng argues, manifests itself in the excess of positive affective feelings over negative affective feelings. Moreover, a measure of affective experience may be a relevant criterion for evaluating economic outcomes (see, for a similar point, Kahneman et al. 1997).

Therefore, deeper insights into the psychology, physiology, and neurobiology of emotion and feelings may be helpful for the formulation of principles and policies capable of reducing distress and increasing human well-being. The fact that affective experiencing is so important in guiding cognitive and social decision-making calls for a revision of behavioral models relying on rationality as the major source of human actions (see also Layard 2006).

For example, evidence from psychology supports the idea that acting in flow and creating harmony between goals and desires, sensations and experiences, challenges and skills improves subjective well-being (see Csikszentmihalyi 1993, Ch. 7; Damasio 2003, p. 131). According to Csikszentmihalyi (1990, p. 34), flow experience is important to understand the strivings of the self and the quality of individual well-being. Flow, he argues, is a sense that humans have developed in order to identify patterns of behavior that are worth pursuing and increasing individual well-being. ${ }^{12}$

On the other hand, an agent's inability to cope with a challenging environment causes confusion, frustration, and negative affect. If skills and cognitive resources do not correspond to challenges, agents tend to be worried and anxious. In the case of diverging skills and challenges, economic dynamics that induce too many challenges within a certain period of time may be welfare-reducing (see Hypothesis 2). ${ }^{13}$ Beyond a certain degree of challenge-introducing competition, there is a tradeoff between the ferocity of the competitive environment and the conditions under which human well-being is effectively fostered.

Evolution-including economic evolution-fundamentally depends upon variation. It is a two-step process: it consists of (a) the generation of new variants; and (b) the replacement of older by newer variants (see Endler and McLellan 1988). This competitive process requires variation and simultaneously acts to reduce variation, a fact that makes necessary processes that continuously produce new variation (Price 1995). ${ }^{14}$

Human variety-introducing creativity is the fundamental driving force behind economic evolution (see Metcalfe 2002). The continuous generation of variety is the crucial characteristic of cultural evolution in regard to its great pace of change. Innovative responses, for example, problem solving or the active search for different models of business, are based on the motivation and capability to be creative. However, as is

\footnotetext{
12 Flow can happen in nearly any kind of activity, at any time, provided that the agent's skills match the opportunities for action in the environment.

13 According to Mokyr (2002, p. 232), technical progress is almost never Pareto-superior: in the presence of vintage-specific skills or unmalleable assets there are members in society who fail to cope with new challenges.

14 Competition can be defined as any mutual influence as a result of which one form of behavior is spreading more successfully than another one when they are present in the same environment, and as a result displaces the second form (Jongeling 1996). Increasing intensity of competition should result in a decrease in different forms of behavior. Thus, it seems reasonable to relate competition inversely to diversity.
} 
indicated by the findings presented in this paper, some competitive environments are more conducive to an expression of human creativity than others. The reasons are to be found in the psychological and physiological aspects of human nature. ${ }^{15}$ For example, positive affect fosters creativity and problem solving. Thus, environments that induce positive affect can be assumed to be conducive to human cognitive performances.

Moreover, an organism's activation or arousal level, which depends inter alia on novelty and challenges induced by a competitive environment, is an important determinant of effectiveness of (creative) performance (Hebb 1955; Fiske and Maddi 1961; Field et al. 1985; Kaufman 1999). Again, the function relating the two variables is typically considered to be an inverted U: at low levels of activation, an agent may be inattentive and easily distracted, devoting little energy to problem solving. At somewhat higher levels, the organism is alert and attentive, thereby mobilizing his resources to cope effectively with the situation (see also Kahneman 1973; Revelle and Loftus 1990).

However, still higher levels of activation associated with excessive tension and strong emotional states such as anxiety appear, causing behavior to be less effective. ${ }^{16}$ An intermediate level of activation associated with positive affect allows for effective (creative) performance, whereas extreme regions of high and low activation impair this performance. A great amount of research has shown that positive affect improves creative problem solving, facilitates recall of neutral and positive material, fosters cognitive elaboration, and systematically changes strategies used in decision-making (see, for references, Ashby et al. 1999; Friedman and Förster 2005). An agent's behavior seeks to modify its activation level toward the optimal zone for the task at hand and his well-being. The achievement of specific goals and the solving of problems aid in maintaining normal activation level.

If an agent experiences moderate degrees of novelty and unexpectedness, for example, during education or socialization, unexpectedness and novelty would have been of such magnitude as to arouse positive affect and would have been associated with the latter. An individual will then perform in a manner likely to produce novel events himself or will seek out situations linked to unexpected occurrences (see Maddi 1961b). These factors also contribute to an agent's creative performance.

Moreover, all evolving systems exhibit some source of resistance to change (see, example, Mayr 1991, 160f), for too much receptivity to change will result in chaos. However, a cohesive force that limits the amount and rate of change always has to be a compromise between excessive conservatism and excessive malleability. Metcalfe (2001) argued that evolutionary systems are always characterized by a considerable degree of inertia and that quasi-stable relations are a prerequisite of creative change. Consequently, he argues, novelty is crucial but so is stability; not everything can be permanently questioned and challenged at the same time. Change is premised on

\footnotetext{
15 There is yet another finding important in this context: cooperative strategies in normal individuals lead to the activation of regions involved in the release of dopamine and in pleasure behavior, thus rewarding and reinforcing cooperation (Rilling et al. 2002). This inclination toward cooperation contradicts economic systems that are based solely on competition.

16 Kaufman (1999) has argued that excessive emotional arousal also contributes to bounded rationality in human behavior. Moreover, the optimal level of arousal seems to be lower the more complex the task at hand.
} 
continuity. Only in the confidence to take many things for granted humans find the scope for creative activity. Competition 'red in tooth and claw' may well destroy the longer term ability to maintain innovative progress (see Metcalfe 2003). This paper provides an explanation of why a certain amount of continuity is important given humans' cognitive dispositions.

On the one hand, a certain degree of competition promotes the efficient utilization of resources and the introduction of innovations. On the other hand, it may-in its excessive forms - finally reduce the generation of variety within a system and thus its adaptability, without necessarily returning to conditions in which positive affect is re-established and again promoting the introduction of novelty. A competitive environment that is too severe may finally inhibit innovation. Thus, competition may affect the source of variety in behavior on which it depends. A similar position is taken by Commons (1934, 763ff): he argues that competition promotes economic efficiency up to a certain point. However, when the competitive environment demands too much from the human agent over-extending his capability to cope, then competition may result in affective disturbances, such as, in his words, maladaptive and anti-social behaviors, essentially compromising economic performance (see also Kaufman 1998). Discussing public policy measures, Layard (2006) suggested the introduction of a corrective income tax in order to 'short circuit the rat race' of working people and increase overall well-being. In his view, competitive economic systems where everyone else appears as a threat are not fostering subjective well-being, even if they generate massive outputs.

An important goal of social institutions is the regulation of life in a particular competitive environment that exerts a certain influence on human well-being. Hence, economic policy makers may scrutinize whether there should be institutional constraints on innovativeness or whether an institutional setting should determine the pace of economic development and competition. Moreover, if other means, which are alternative to competition-driven change, are more conducive to meet the ends humans pursue in certain spheres, then competition may be judged, not as good or bad, but as inefficient (for a similar argument see Commons 1934; Brozen 1952). These would be new challenges for institutional economics.

The Schumpeterian entrepreneurs play an important role in the introduction of novelty to the economy (Schumpeter 1934). These agents carry out major innovations and thus promote waves of economic development and growth. Thereby, on the one hand, they contribute to the overall amount of novelty and change experienced by the actors in an economic system and present new challenges to them-a phenomenon addressed as a process of 'creative destruction'. On the other hand, the first entrepreneurs must be able to enjoy a temporary monopoly that enables them to earn 'promoter's profits'. Innovators become a 'social model of behavior' (Bandura 1986, Ch. 2) that is copied by other agents and induce a 'swarm-like' appearance of entrepreneurs that marks the beginning of the life cycle of a new industry (Witt and Cordes 2007). Extremely competitive environments and a corresponding low rate of entrepreneurial success may impair this dynamic that is based on processes of social-cognitive learning from positive role models.

In his later work, Schumpeter (1942) no longer believed in the path-breaking role of entrepreneurs. Instead, he directed his interest to the large, modern trust and its bureaucratic teams of trained specialists that carry out innovations as routine work. 
However, Schumpeter still focused on the effects of high degrees of competition resulting from this kind of innovation regime: according to him, an important implication of the trust's incessant, competition-driven innovativeness was that these would finally embrace monopolistic practices as a necessary concomitant (Ch. 8). Game-theoretic models of Schumpeterian 'innovation races' show the effects of this kind of furious competition on market structure (e.g., Reinganum 1985).

Although individuals exhibit differences in their variation-seeking behavior and their handling of challenges-due to socialization effects, learning, natural disposition, or the resources and skills that they have at their disposal-they all face an upper boundary of habituation to, and positive evaluation of, novelty and of their capability to cope effectively with a challenging environment without experiencing strained life states. Novel stimuli, for example, elicit amplified affective experiences that are highly resistant to habituation (Kahneman and Miller 1986; Ranganath and Rainer 2003). Therefore, within limits, the inverted U-shaped relationship between the degree of novelty and an individual agent's well-being mentioned in Section 2 can-in the course of habituation-be shifted toward higher amounts of novel stimuli.

However, as a consequence of these individual differences and the ambiguous effects of novelty and challenges discussed earlier in this paper, there are competitive, stimuli providing environments where, for example, agents who appreciate a higher amount of novelty benefit, while other agents, who have a lower upper boundary of adaptation to novelty, suffer from decreases in their well-being, when faced with the same level of stimulation. It is not easy for a policy maker to balance this two-sidedness of competition and individual experiences. There may be areas in a society, for example, science, where a higher level of competition may be stimulating, while the same level of competition may inhibit activities and well-being in other occupational fields. As a consequence, policy making has to take into account different domains of life. It should tailor social institutions to the regulation of life, in particular areas of activity and competitive environments as well as to the agents involved, especially in regard to their educational background. In any case, sooner or later, a threshold beyond which negative affective experiences prevail is reached in all these realms, by all the individuals. Moreover, experiences regarding changes in fundamental aspects of life, such as the family, the social milieu, or the basis of livelihood are probably affectively evaluated in very similar ways across individuals.

The societal acceptance of novelty could be increased by offering temporary special protection or assistance to agents who have invested in certain 'vintages' of skills, capital, or occupations, for example, by delaying the introduction of novelty. In these cases, some time would be given to them enabling an adaptation to changing circumstances, keeping challenges and personal resources in line with each other, and relieving uncertainty, thereby potentially avoiding strained life states of those affected. In addition, the willingness to invest in assets subject to vintage effects may increase due to such a protection. The aggregated welfare effects of these kinds of political intervention may overcompensate losses accruing from a postponed novelty-induced structural change of the economy.

Other potential political implications result from a consideration of the long term effects of novelty: while, in the short run, people may (affectively) suffer from a high amount of novelty introduced to them, its longer term consequences may be positive. 
Technological innovations, for example, often impair the position of some members of society but may ultimately lead to an improvement of overall living conditions. Hence, what shows up in this context are externalities of novelty that may even affect different generations of actors. Policy makers may think about ways to alleviate these external effects by devising means that balance the differential repercussions of novelty, such as, for example, intergenerational funds. ${ }^{17}$ This potentially positive long term effect of novelty is lost if the competition-driven introduction of novelty nontransiently exceeds the individuals' want for a certain amount of novel stimuli and thus permanently impairs social well-being.

Possibly, there is also a connection between the acceptance of policy reforms and the overall amount of novelty and challenges brought to the agents: if policy makers provide a kind of basic security, i.e., if they keep away novelty and uncertainty from the agents in some domains of life, this may ease the introduction of novel elements to the economy in other areas. Moreover, if people receive some basic social security, such as health care, a certain degree of protection against dismissal, unemployment insurance, or a guaranteed pension scheme, a society may be more receptive to change and reform in general. The acceptance of political measurements and institutional change in a society can then be raised when accompanied by the explicit retention of some aspects of life, thereby channeling and restricting the amount of novelty and challenges introduced to the agents. This would be an unorthodox justification for state activity in these realms based on insights into cognitive and affective aspects of human agents that are rarely accounted for by economists.

In the context of this paper's argument, a central problem for any policy maker is the specification of the threshold beyond which novelty and challenges introduced by a competitive environment are evaluated negatively by an agent. There are objective measures detecting positive and negative affect in subjects depending on their environment; the human brain constructs a running affective commentary that permanently evaluates experiences. ${ }^{18}$ Therefore, Kahneman (1999) has argued, an assessment of a person's objective happiness over a period of time is possible by recording the quality of experience at each point, i.e., by measuring the relative frequencies and durations of positive and negative affect (see also Panksepp 2003b).

Thus, real-time measures of present experience can be obtained and aggregated to yield a measure of objective well-being (see also Ito and Cacioppo 1999). Questions about well-being and general happiness may be answered on a scientific, objective, naturalistic, and reproducible basis. A combination of methods will be necessary to characterize the objective well-being of individuals and groups. This will ultimately enable a bottom-up approach to the analysis of well-being and the aggregating of differences in individual experiences (Ng 1997; Kahneman 1999). More general happiness questions could be answered by sampling domains of life and assessing their

\footnotetext{
17 This argument is similar to the Kaldor-Hicks criterion prominent in welfare economics: an economic situation is superior to another when the welfare gains of potential winners exceed the welfare losses of potential losers such that the latter could be potentially compensated by the winners (Hicks 1939; Kaldor 1939).

18 Methods from psychophysiology, psychoendocrinology, behavioral analysis, and brain biochemistry enable the measurement of arousal and affect in different situations (for references see Ursin and Eriksen 2004).
} 
status with respect to well-being. In principle, it should be possible to examine the affective experiences of representative individuals in a society and to draw conclusions even for an aggregated approach to policy making.

In addition, social indicators and subjective well-being measures are important to evaluate a society and add substantially to economic indicators that are usually preferred by policy makers (see Diener and Eunkook 1997). An examination of correlations of certain predictor variables with subjective well-being measures could include variables such as precarious employment, change of the place of residence or the social milieu, necessary adaptations to new equipment at the workplace, amount of new problems arising at the workplace within a certain time span, or other measures of change and novelty in an individual's environment. It may then be possible to determine the threshold beyond which most agents start to evaluate their environment as strained and in an affectively negative way. By this means, information can be offered to the agents concerning the impact of the state of the economy and the institutional conditions on subjective well-being. The individuals can then take into account these information and introduce them to the political process.

Frey and Stutzer (2002, p. 15) have shown that political decentralization and the possibility of political participation affect subjective well-being in a positive way. This may be due to an increased range of an agent's perceived possibilities to cope directly with the challenges posed by the environment, a feeling of control, and extended selfdetermination (see Hypothesis 2). The approach brought forward in this paper may thus provide some of the cognitive underpinnings of such an effect.

Potentially, there are two levels at which policy makers could intervene: first, within certain boundaries, individuals can adapt to increasing novelty by shifting their arousal function toward a need for a greater amount of novel stimuli. Socialization processes and an educational system that take advantage of this human capability would prepare agents to cope with a rapidly changing environment and would foster a culture of innovativeness. Second, which is a more ambitious challenge for policy making, an institutional set up could be necessary that prevents too much change in the agents' environments and too many challenges posed to them. Policy measures may comprise, for example, regulations on too excessive forms of precarious employment or even on innovativeness as such.

To conclude, there are two major possible consequences of an excessive degree of competition: (a) the agent's creative potential may be inhibited and thus the crucial source of variety in an economic system as well as his overall economic performance; or (b) people may feel unpleasant, given their competitive environment, and thus an important political goal-the enhancement of welfare-would be missed. A too great pace of innovativeness may, while increasing per capita real income, impair the wellbeing of economic agents.

The following hypothesis is proposed:

Hypothesis 3 Given the insights of Hypotheses 1 and 2, an excessive amount of novelty and a too challenging environment impair human performance and well-being. What is more, given the fact that competition introduces novelty and new challenges to an economic system, there should be limits to competition-driven economic dynamics that are to be found within human beings. 


\section{Conclusions}

Potential conflicts between the evolved cognitive endowments of humans on the one hand, and the dynamics of economic development on the other, have not been the subject matter of profound inquiry in economics. This paper has shown that evidence from various disciplines indicates that there are indeed limits to economic dynamics that are to be found in the cognitive setup of human agents. ${ }^{19}$

First, the human want for novelty, while it is certainly susceptible to cultural conditioning, has limits imposed on it by psycho-physiological factors. Too much novelty is associated with negative affect. Second, competitive environments that over-exert an agent's skills and (cognitive) resources result in strained life states that impair individual well-being and (creative) performance. Consequently, a competitive environment introducing novelty and challenges to the agents that is too severe may decrease human well-being. Some implications for economic theory and policy making have been shown.

Human consciousness still reflects the evolutionary continuities that can be found in the organic emergence of the human brain and that still impose constraints on economic behavior and development, in the sense that what is optimal, desirable, or appropriate in the world of pure economic theory may not be compatible with the peculiarities of real world human beings.

Acknowledgements I thank Guido Bünstorf, Janet Landa, Michael Ghiselin, and an anonymous economist referee for helpful comments for the revision of the paper.

Open Access This article is distributed under the terms of the Creative Commons Attribution Noncommercial License which permits any noncommercial use, distribution, and reproduction in any medium, provided the original author(s) and source are credited.

\section{References}

Anderson, K. J. (1990). Arousal and the inverted-U hypothesis: A critique of Neiss's 'Reconceptualizing Arousal'. Psychological Bulletin, 107(1), 96-100.

Ashby, G. F., Isen, A. M., \& Turken, U. (1999). A neuropsychological theory of positive affect and its influence on cognition. Psychological Review, 106(3), 529-550.

Bandura, A. (1986). Social foundations of thought and action. Englewood Cliffs: Prentice-Hall.

Bardo, M. T., Donohew, R. L., \& Harrington, N. G. (1996). Psychobiology of novelty seeking and drug seeking behavior. Behavioural Brain Research, 77(1-2), 23-43.

Bechara, A., Hanna D., \& Damasio, A. R. (2000). Emotion, decision making and the Orbitofrontal cortex. Cerebral Cortex, 10(3), 1047-3211.

Berlyne, D. E. (1960). Conflict, arousal, and curiosity. New York: McGraw-Hill.

Berlyne, D. E. (1971). Aesthetics and psychobiology. New York: Appleton Century Crafts.

Bianchi, M. (2002). Novelty, preferences, and fashion: When goods are unsettling. Journal of Economic Behavior and Organization, 47, 1-18.

Brozen, Y. (1952). The value of technological change. Ethics, 62(4), 249-265.

\footnotetext{
19 It is important to remark that the limits to competition identified in this paper are no principal constraint to economic activity - there may be a high degree of competition while people suffer from severe losses in their well-being. Rather, this constraint takes effect when policy makers put the human well-being and their affective evaluations of situations center stage in their political endeavors.
} 
Buck, R. (1985). Prime theory: An integrated view of motivation and emotion. Psychological Review, 92(3), 389-413.

Cicchetti, D., \& Pogge-Hesse P. (1981). The relation between emotion and cognition in infant development. In M. E. Lamb \& L. R. Sherrod (Eds.), Infant social cognition (pp. 205-272). Hillsdale, NJ: Erlbaum.

Commons, J. R. (1921) Industrial government. International Labour Review, 1(1), 61-67.

Commons, J. R. (1934). Institutional economics. New York: Macmillan.

Csikszentmihalyi, M. (1990). Flow. New York: Harper \& Row.

Csikszentmihalyi, M. (1992). The flow experience and its significance for human psychology. In M. Csikszentmihalyi \& I. S. Csikszentmihalyi (Eds.), Optimal experience (pp. 15-35). Cambridge: Cambridge University Press.

Csikszentmihalyi, M. (1993). The evolving self. New York: HarperCollins.

Damasio, A. R. (1996). The somatic marker hypothesis and the possible functions of the prefrontal cortex. Philosophical Transactions: Biological Sciences, 351(1346), 1413-1420.

Damasio, A. R. (2003). Looking for Spinoza. London: William Heinemann.

Diener, Ed., \& Eunkook, S. (1997). Measuring quality of life: Economic, social, and subjective indicators. Social Indicators Research, 40, 189-216.

Emmons, R. A. (1986). Personal strivings: An approach to personality and subjective well-being. Journal of Personality and Social Psychology, 51(5), 1058-1068.

Endler, J. A., \& McLellan, T. (1988). The processes of evolution: Toward a newer synthesis. Annual Review of Ecology and Systematics, 19, 395-421.

Field, T. M., McCabe, P. M., \& Schneiderman, N. (1985). Stress and coping. Hillsdale, NJ: Lawrence Erlbaum.

Fiske, D. W., \& Maddi, S. R. (1961). A conceptual framework. In D. W. Fiske \& S. R. Maddi (Eds.), Functions of varied experience (pp. 11-56). Homewood: Dorsey Press.

Frey, B. S., \& Stutzer, A. (2002). Happiness and economics. Princeton: Princeton University Press.

Friedman, D., Cycowicz, Y. M., \& Gaeta, H. (2001). The novelty P3: An event-related brain potential (ERP) sign of the brain's evaluation of novelty. Neuroscience and Biobehavioral Reviews, 25, 355-373.

Friedman, R. S., \& Förster, J. (2005). Effects of motivational cues on perceptual asymmetry: Implications for creativity and analytical problem solving. Journal of Personality and Social Psychology, 88(2), 263-275.

Giddens, A. (1994). Beyond left and right. Cambridge: Polity Press.

Hebb, D. O. (1955). Drives and the CNS. Psychological Review, 62(4), 243-254.

Hicks, J. R. (1939). The foundations of welfare economics. The Economic Journal, 49(196), 696-712.

Ito, T. A., \& Cacioppo, J. T. (1999). The psychophysiology of utility appraisals. In D. Kahneman, E. Diener, \& N. Schwarz (Eds.), Well-being: The foundations of hedonic psychology (pp. 470-488). New York: Russell Sage Foundation.

Jongeling, T. B. (1996). Self-organization and competition in evolution: A conceptual problem in the use of fitness landscapes. Journal of Theoretical Biology, 178, 369-373.

Kagan, J. (1972). Motives and development. Journal of Personality and Social Psychology, 22(1), 51-66.

Kahneman, D. (1973). Attention and effort. Englewood Cliffs, NJ: Prentice-Hall.

Kahneman, D. (1999). Objective happiness. In E. Diener, D. Kahneman, \& N. Schwarz (Eds.), Well-being: The foundations of hedonic psychology (pp. 3-25). New York: Russell Sage Foundation.

Kahneman, D., \& Miller, D. T. (1986). Norm theory: Comparing reality to its alternatives. Psychological Review, 93(2), 136-153.

Kahneman, D., Wakker, P. P., \& Sarin, R. (1997). Back to Bentham? Explorations of experienced utility. Quarterly Journal of Economics, 112(2), 375-405.

Kaldor, N. (1939). Welfare propositions of economics and interpersonal comparisons of utility. The Economic Journal, 49(195), 549-552.

Kaufman, B. E. (1998). Regulation of the employment relationship: The 'old' institutional perspective. Journal of Economic Behavior and Organization, 34, 349-385.

Kaufman, B. E. (1999). Emotional arousal as a source of bounded rationality. Journal of Economic Behavior and Organization, 38, 135-144.

Layard, R. (2006). Happiness and public policy: A challenge to the profession. The Economic Journal, 116(510), C24-C33.

Leuba, C. (1955). Toward some integration of learning theories: The concept of optimal stimulation. Psychological Reports, 1, 27-33. 
Loewenstein, G. (1994). The psychology of curiosity: A review and reinterpretation. Psychological Bulletin, 116(1), 75-98.

Maddi, S. R. (1961a). Exploratory behavior and variation-seeking in man. In D. W. Fiske \& S. R. Maddi (Eds.), Functions of varied experience (pp. 253-277). Homewood: Dorsey Press.

Maddi, S. R. (1961b). Unexpectedness, affective tone, and behavior. In D. W. Fiske \& S. R. Maddi (Eds.), Functions of varied experience (pp. 380-401). Homewood: Dorsey Press.

Mayes, L. C. (1991). Exploring internal and external worlds-reflections on being curious. Psychoanalytic Study of the Child, 46, 3-36.

Mayr, E. (1991). One long argument: Charles Darwin and the genesis of modern evolutionary theory. Cambridge, MA: Harvard University Press.

McCall, R. B., Kennedy, C. B., \& Appelbaum, M. I. (1977). Magnitude of discrepancy and the distribution of attention in infants. Child Development, 48(3), 772-785.

Metcalfe, S. J. (2001). Institutions and progress. CRIC Discussion Paper, 45, 1-28.

Metcalfe, S. J. (2002). Knowledge of growth and the growth of knowledge. Journal of Evolutionary Economics, 12, 3-15.

Metcalfe, S. J. (2003). Equilibrium and evolutionary foundations of competition and technology policy: New perspectives on the division of labour and the innovation process. In P. Pelikan \& G. Wegner (Eds.), The evolutionary analysis of economic policy (pp. 162-190). Cambridge, MA: Edward Elgar.

Mitchell, R. G. Jr. (1992). Sociological implications of the flow experience. In M. Csikszentmihalyi \& I. S. Csikszentmihalyi (Eds.), Optimal experience (pp. 36-59). Cambridge: Cambridge University Press.

Mokyr, J. (2002). The gifts of Athena. Historical origins of the knowledge economy. Princeton: Princeton University Press.

Morris, W. N. (1999). The mood system. In D. Kahneman, E. Diener, \& N. Schwarz (Eds.), Well-being: The foundations of hedonic psychology (pp. 169-189). New York: Russell Sage Foundation.

Munsinger, H., \& Kessen, W. (1966). Stimulus variability and cognitive change. Psychological Review, 73(2), 164-178.

Najm-Briscoe, R. G., Thomas, D. G., \& Overton, S. (2000). The impact of stimulus 'value' in infant novelty preference. Developmental Psychobiology, 37(3), 176-185.

Nelson, R. R. (1990). Capitalism as an engine of progress. Research Policy, 19, 193-214.

Ng, Y.-K. (1997). A case for happiness, cardinalism, and interpersonal comparability. The Economic Journal, 107(445), 1848-1858.

Ng, Y.-K. (2003). From preference to happiness: Towards a more complete welfare economics. Social Choice and Welfare, 20, 307-350.

Panksepp, J. (2003a). An archaeology of mind: The ancestral sources of human feelings. Soundings, $86(1-2), 41-69$.

Panksepp, J. (2003b). At the interface of the affective, behavioral, and cognitive neurosciences: Decoding the emotional feelings of the brain. Brain and Cognition, 52, 4-14.

Peterson, C. (1999). Personal control and well-being. In D. Kahneman, E. Diener, \& N. Schwarz (Eds.), Wellbeing: The foundations of hedonic psychology (pp. 288-301). New York: Russell Sage Foundation.

Piaget, J. (1952). The origins of intelligence in children. New York: International Universities Press.

Price, G. R. (1995). The nature of selection. Journal of Theoretical Biology, 175, 389-396.

Ranganath, C., \& Rainer, G. (2003). Neural mechanisms for detecting and remembering novel events. Nature Reviews Neuroscience, 4(3), 193-202.

Reinganum, J. F. (1985). Innovation and industry evolution. Quarterly Journal of Economics, 100(1), 81-99.

Revelle, W., \& Loftus, D. A. (1990). Individual differences and arousal: Implications for the study of mood and memory. Cognition and Emotion, 4(3), 209-237.

Rilling, J. K., Gutman, D. A., Zeh, T. R., Pagnoni, G., Berns, G. S., \& Kilts, C. D. (2002). A neural basis for social cooperation. Neuron, 35, 395-405.

Rule, R. R., Shimamura, A. P., \& Knight, R. T. (2002). Orbitofrontal cortex and dynamic filtering of emotional stimuli. Cognitive, Affective, \& Behavioral Neuroscience, 2(3), 264-270.

Schumpeter, J. A. (1934). The theory of economic development. Cambridge, MA: Harvard University Press. Schumpeter, J. A. (1942). Capitalism, socialism and democracy. New York: Harper \& Brothers.

Scitovsky, T. (1981). The desire for excitement in modern society. Kyklos, 34(1), 3-13.

Steriade, M. (1996). Arousal: Revisiting the reticular activating system. Science, 272(5259), 225-226.

Thompson, E., \& Varela, F. J. (2001). Radical embodiment: Neural dynamics and consciousness. TRENDS in Cognitive Sciences, 5(10), 418-425. 
Ursin, H., \& Eriksen, H. R. (2004). The cognitive activation theory of stress. Psychoneuroendocrinology, 29, 567-592.

Wasserman, E. A., Young, M. E., \& Cook, R. G. (2004). Variability discrimination in humans and animals. American Psychologist, 59(9), 879-890.

White, R. W. (1959). Motivation reconsidered-the concept of competence. Psychological Review, 66(5), 297-333.

Witt, U. (1996). Innovations, externalities and the problem of economic progress. Public Choice, 89, $113-130$.

Witt, U. (2003a). Economic policy making in evolutionary perspective. Journal of Evolutionary Economics, 13, 77-94.

Witt, U. (2003b). The evolving economy-essays on the evolutionary approach to economics. Cheltenham: Edward Elgar.

Witt, U. (2004). On the proper interpretation of 'evolution' in economics and its implications for production theory. Journal of Economic Methodology, 11(2), 125-146.

Witt, U., \& Cordes, C. (2007). Selection, learning, and Schumpeterian dynamics-a conceptual debate. In H. Hanusch \& A. Pyka (Eds.), The Elgar companion to neo-Schumpeterian economics (pp. 316-328). Cheltenham: Edward Elgar.

Wundt, W. (1894). Lectures on human and animal psychology. London: Swan Sonnenschein \& Co.

Zuckerman, M. (1994). Behavioral expressions and biosocial bases of sensation seeking. Cambridge: Cambridge University Press. 